\title{
The clinical importance of gram-positive anaerobic cocci isolated at St Bartholomew's Hospital, London, in 1987
}

\author{
D. A. MURDOCH*, I. J. MITCHELMORE and S. TABAQCHALI
}

Department of Microbiology, St Bartholomew's Hospital, London EC1A 7BE

\begin{abstract}
Summary. The clinical importance of the gram-positive anaerobic cocci (GPAC) isolated in 1987 at St Bartholomew's Hospital, London, is assessed. Of about 800 anaerobic isolates, 209 $(27 \%)$ were GPAC, of which $67(32 \%)$ were from abscesses and $22(11 \%)$ were in pure growth. Four species comprised $77 \%$ of the 168 isolates available for study: Peptostreptococcus magnus (55 isolates, $33 \%)$, P. micros $(23,14 \%)$, P. asaccharolyticus $(24,14 \%)$ and $P$. anaerobius $(27,16 \%)$. Different species were associated with different sites, from $P$. magnus (usually skin-associated sites; normally cultured with aerobes, infrequently with other anaerobes), $P$. asaccharolyticus (distributed widely) and $P$. anaerobius (usually genitourinary and gastrointestinal; always below the diaphragm) to $P$. micros (always deep sites with other anaerobes). $P$. magnus was isolated from 15 abscesses and was obtained in pure culture from 11 specimens, six of them abscesses developing from infected sebaceous cysts. P. micros was usually isolated from soft tissue abscesses, never from the skin, and with a characteristic mixed flora consisting of "Streptococcus milleri" and anaerobic gram-negative rods. $P$. heliotrinreducens was a rare isolate from similar specimens. P. asaccharolyticus was cultured from a wide variety of sites, typically mixed with both aerobes and anaerobes, and frequently from abscesses. Most isolates of $P$. anaerobius came from gastrointestinal or female genitourinary specimens, never from above the diaphragm and rarely from the skin; cultures were usually heavily mixed. Isolates of $P$. vaginalis and the "bGAL" group made up $11 \%$ of strains and were usually cultured from superficial sites, $P$. vaginalis often from post-operative wound infections with Staphylococcus aureus. There were only two isolates of $P$. hydrogenalis, three of $P$. tetradius and none of $P$. barnesae, $P$. prevotii, $P$. lacrimalis, $P$. lactolyticus, $P$. productus or Peptococcus niger. GPAC are a heterogeneous group associated with a wide variety of infections, particularly abscesses, and are frequently isolated in pure culture. They deserve further study.
\end{abstract}

\section{Introduction}

Gram-positive anaerobic cocci (GPAC), placed in the genera Peptostreptococcus and Peptococcus, are neglected but important human pathogens. They are the second commonest group of anaerobes isolated from clinical sources, consistently accounting for $20-40 \%$ of all anaerobes. ${ }^{1-5}$ However, little is known about the relative importance of individual species because the classification is unsatisfactory ${ }^{6-10}$ and laboratory identification has been unreliable..$^{3.11-13}$ Two recent comparative surveys ${ }^{3,4}$ used identification systems relying heavily on carbohydrate fermentation tests $;^{3,8,13}$ unfortunately, most species of GPAC are asaccharolytic, ${ }^{8,10,14}$ so that differentiation has depended largely on negative results. Thus, cell size is the method usually recommended ${ }^{3,10,12,13}$ to distinguish between two of the most important species, Pepto-

Received 24 Aug. 1993; revised version accepted 15 Jan. 1994.

* Present address and address for correspondence: Department of Microbiology, Southmead Hospital, Bristol BS10 5NB. streptococcus magnus and P. micros. Five new species have been described recently, ${ }^{15-17}$ but there are few data yet on their identification or clinical importance.

The problems with laboratory identification have been lessened by the introduction of pre-formed enzyme kits, ${ }^{10,18-20}$ based on tests for the presence of saccharolytic and proteolytic enzymes. These kits were used to characterise a collection of 256 clinical strains, isolated in 1986-1987 at St Bartholomew's Hospital, London. ${ }^{21}$ Of these strains, $246(96 \%)$ were placed in 12 enzyme groups. There was complete agreement between grouping with pre-formed enzyme kits and the results from volatile fatty acid (VFA) analysis by gas-liquid chromatography (GLC). A detailed analysis of the clinical significance of the 209 isolates of GPAC from 1987 described in that report is now presented.

\section{Materials and methods}

\section{Isolation of anaerobes from patient samples}

Specimens of pus, purulent fluids and antral wash- 
outs for anaerobic culture were inoculated on to Brucella Agar (Difco), with defibrinated horse blood (Oxoid) $6 \%$, haemin (Sigma) $5 \mathrm{mg} / \mathrm{L}$ and vitamin $\mathrm{K} 1$ (Roche) $1 \mathrm{mg} / \mathrm{L}$; a second plate with neomycin (Wellcome) $100 \mathrm{mg} / \mathrm{L}$ was also inoculated. Part of the specimen was inoculated into Robertson's Cooked Meat Broth (Southern Group Labs, London), which was subcultured at $48 \mathrm{~h}$ on to the same media. Cultures were inoculated in air and incubated anaerobically in an atmosphere of $\mathrm{N}_{2} 80 \%, \mathrm{H}_{2} 10 \%$ and $\mathrm{CO}_{2} 10 \%$ for 10 days. The anaerobic chamber used was home-made until August 1987, when a Mark III cabinet (Don Whitley Scientific, Shipley, W Yorks) was brought into use. All anaerobes isolated from these specimens were investigated further. Aerobic cultures were inoculated on to Brucella Agar as above, MacConkey Agar (Oxoid) and, for head and neck specimens, Chocolate Agar (Tissue Culture Services, Botolph Claydon, Bucks). Aerobic cultures were incubated in air + $\mathrm{CO}_{2} 5 \%$ at $37^{\circ} \mathrm{C}$ for $48 \mathrm{~h}$.

Other specimens were inoculated on to pre-poured Blood Agar (Tissue Culture Services) and MacConkey agar, and incubated in air $+\mathrm{CO}_{2}$ and anaerobically, as above, for $48 \mathrm{~h}$, with neomycin and chocolate plates if appropriate. Anaerobic plates from these specimens were incubated in jars equipped with palladium catalysts and Gaspaks (Becton Dickinson, Oxford). Anaerobes isolated from these specimens were recorded and saved for further study only if they were in heavy growth and reasonably pure.

\section{Identification of GPAC}

Strains of GPAC were identified as described previously $;{ }^{21}$ briefly, the techniques used were the gramstained film and colonial morphology, the detection of VFA production by GLC, the pre-formed enzyme profile obtained with the ATB 32A kit (bioMerieux, Basingstoke, Hants), and the antibiotic sensitivity pattern. A Pye-Unicam series 104 gas chromatograph was used for the detection of VFA. Other anaerobes were named and identified according to Holdeman Moore et $\mathrm{l}^{8}$ and the API 20A system (bioMérieux).

\section{Source of clinical information}

The St Bartholomew's Hospital computerised data base was used to list all anaerobic isolates from 1986-1987. Limited information was available from patient request forms; this was supplemented where appropriate by consulting the patients' notes.

\section{Results}

In 1986-1987, 440 strains of GPAC were isolated at St Bartholomew's Hospital; there were 598 strains of gram-negative anaerobic rods, 344 strains of Clostridium spp. (67\% of which were faecal isolates of $C$. difficile) and 18 strains of Veillonella spp. (table I). Of the GPAC isolated in 1986 , only $88(38 \%)$ were still available for study, compared to $168(80 \%)$ of 209 in 1987. Because of the large difference, this report is based on the 1987 strains, although 1986 strains are discussed briefly for rare groups such as $P$. hydrogenalis. Five isolates from 1987 were no longer viable and 36 had not been stored. Data on the other microorganisms with which 1987 isolates were cultured were available in all but four cases $(2 \%)$, but there was no additional clinical information available for another $12(6 \%)$ isolates. Of the 168 available strains, 88 came from pus and other fluids, and 80 from other specimens; $55(33 \%)$ were identified as $P$. magnus, 23 $(14 \%)$ as $P$. micros, $24(14 \%)$ as $P$. asaccharolyticus and $27(16 \%)$ as $P$. anaerobius. These four species represented $77 \%$ of all available strains (table II).

\section{Analysis by site of specimen}

Superficial sites (table III) yielded 71 isolates ( $33 \%$ of total): 34 from the upper body (face, neck, breast, trunk, axilla and umbilicus), 24 from superficial pelvic sites and 13 from the leg. Most were identified as $P$. magnus ( 28 of the 59 isolates available for study, $48 \%$ ). Of the 34 isolates from superficial sites on the upper body, $20(59 \%)$ were from abscesses (including $10 P$. magnus and five $P$. asaccharolyticus strains; table IV). The pelvic strains were isolated from the perineum, superficial groin or thigh wounds and pressure sores, and were frequently accompanied by a heavy mixed culture suggestive of faecal contamination; only six $(25 \%)$ were from abscesses. The superficial sites on the leg were mostly ulcers or infected post-surgical wounds; none was an abscess. Thirteen isolates from superficial sites were cultured pure, of which eight (including six $P$. magnus) were from infected sebaceous cysts on the upper body and five (including three $P$. magnus) were from post-operative wounds. Staphylococcus aureus was cultured from nine $(69 \%)$ of 13 specimens from the leg but from only six $(18 \%)$ of the 34 specimens from the upper body. There were only

Table I. Comparison of groups of anaerobic bacteria isolated at St Bartholomew's Hospital 1986-1987

\begin{tabular}{l|rrr}
\hline & \multicolumn{3}{|c}{ Number of isolates in } \\
\cline { 2 - 4 } Anaerobic groups & 1986 & 1987 & Total \\
\hline Gram-negative rods & & & \\
$\quad$ Bacteroides* & 197 & 283 & 480 \\
Fusobacterium & 22 & 46 & 68 \\
$\quad$ Unidentified & 46 & 4 & 50 \\
Total & $\mathbf{2 6 5}$ & $\mathbf{3 3 3}$ & $\mathbf{5 9 8}$ \\
Veillonella spp. & $\mathbf{6}$ & $\mathbf{1 2}$ & $\mathbf{1 8}$ \\
Clostridium spp. & & & \\
$\quad$ faecal & 69 & 164 & 233 \\
other sites & 47 & 64 & 111 \\
Total & $\mathbf{1 1 6}$ & $\mathbf{2 2 8}$ & $\mathbf{3 4 4}$ \\
GPAC & $\mathbf{2 3 1}$ & $\mathbf{2 0 9}$ & $\mathbf{4 4 0}$ \\
\end{tabular}

* The genus Bacteroides is defined according to the 2nd edition of Bergey's Manual of Systematic Bacteriology, in use when these isolates were identified. 
Table II. Number of isolates of GPAC and organisms with which they were cultured

\begin{tabular}{|c|c|c|c|c|c|c|}
\hline \multirow{2}{*}{ Species } & \multicolumn{2}{|c|}{$\begin{array}{l}\text { Number }\left(\%^{*}\right) \text { of } \\
\text { isolates of GPAC }\end{array}$} & \multicolumn{4}{|c|}{$\begin{array}{l}\text { Number }(\%) \text { of specimens from which } \\
\text { associated organisms were isolated }\end{array}$} \\
\hline & Total & $\begin{array}{l}\text { Isolated } \\
\text { pure }\end{array}$ & $\begin{array}{l}\text { Aerobic/ } \\
\text { facultative }+\end{array}$ & S. aureus & "Str. milleri" & $\begin{array}{l}\text { Obligate } \\
\text { anaerobes }\end{array}$ \\
\hline \multicolumn{7}{|l|}{ VFA-negative group } \\
\hline P. magnus & 55 & $11(20)$ & $42(76)$ & $12(22)$ & $2(4)$ & $19(35)$ \\
\hline P. micros & 23 & 0 & $12(55)$ & $2(9)$ & $8(36)$ & $22(96)$ \\
\hline$P$. heliotrinreducens & 5 & 0 & $2(40)$ & 0 & $2(40)$ & $5(100)$ \\
\hline Unidentified & 1 & 0 & 1 & 0 & 0 & 1 \\
\hline \multicolumn{7}{|l|}{ Butyric group } \\
\hline$P$. asaccharolvticus & 24 & $3(12)$ & $21(87)$ & $3(12)$ & $2(8)$ & $19(79)$ \\
\hline P. indolicus & 1 & 1 & 0 & 0 & 0 & 0 \\
\hline$P$. tetradius & 3 & 0 & 3 & 0 & 0 & 3 \\
\hline$P$. vaginalis & 10 & $1(10)$ & $7(70)$ & $5(50)$ & 0 & $1(10)$ \\
\hline "bGAL" group & 8 & 0 & $5(63)$ & $1(12)$ & 0 & $6(75)$ \\
\hline$P$. hydrogenalis & 2 & 0 & 1 & 0 & 0 & 1 \\
\hline Other & 6 & 0 & 5 & 2 & 0 & 5 \\
\hline Isovaleric group & & & & & & \\
\hline "Ivoricus" group & 1 & 0 & 1 & 0 & 0 & 1 \\
\hline Isocaproic group & & & & & & \\
\hline$P$. anaerobius & 27 & $1(4)$ & $19(73)$ & $4(15)$ & $3(\mathrm{II})$ & $20(77)$ \\
\hline Caproic group & & & & & & \\
\hline Hare group VIII & 2 & 0 & 2 & 0 & 0 & 1 \\
\hline Total & 168 & & & & & \\
\hline
\end{tabular}

* The numbers in brackets refer to the percentage of all isolates of that species.

$\dagger$ The isolates of "Str. milleri" were not included in "aerobic/facultative organisms".

Table III. Isolation of GPAC from selected superficial sites

\begin{tabular}{|c|c|c|c|c|c|c|c|c|}
\hline \multirow[b]{2}{*}{ Species } & \multicolumn{7}{|c|}{ Number of isolates from } & \multirow{2}{*}{ Total $(\%)$} \\
\hline & $\begin{array}{l}\text { face and } \\
\text { neck }\end{array}$ & axilla & breast & $\begin{array}{l}\text { skin of } \\
\text { trunk }\end{array}$ & umbilical & $\begin{array}{l}\text { superficial } \\
\text { pelvic }\end{array}$ & $\begin{array}{l}\text { superficial } \\
\text { leg }\end{array}$ & \\
\hline P. magnus & 4 & 3 & 1 & 3 & 4 & 8 & 5 & $28(51)^{*}$ \\
\hline P. micros & & & & & & & & 0 \\
\hline P. heliotrinreducens & & & & 1 & & & & $1(20)$ \\
\hline P. asaccharolyticus & 2 & & 2 & 1 & & 4 & & $9(38)$ \\
\hline$P$. vaginalis & & & & 1 & & 2 & 3 & $6(60)$ \\
\hline "bGAL" group & & & 2 & 1 & & 3 & & $6(75)$ \\
\hline$P$. hydrogenalis & & & & 2 & & & & $2(100)$ \\
\hline $\begin{array}{l}\text { Other butyrate- } \\
\text { producing }\end{array}$ & & & & & 1 & 1 & 1 & 3 \\
\hline$P$. anaerobius & & & & & 1 & 2 & 1 & $4(15)$ \\
\hline Unsaved strains & 1 & 1 & 1 & 2 & & 4 & 3 & 12 \\
\hline Total & 7 & 4 & 6 & 11 & 6 & 24 & 13 & 71 \\
\hline
\end{tabular}

* Number in brackets refers to the percentage of all isolates of that species.

four isolates of $P$. anaerobius and none of $P$. micros from skin-associated sites.

Deep sites from above the diaphragm (table V) yielded 35 strains of GPAC (17\%); the dominant species at most sites was $P$. micros, which accounted for 15 $(47 \%)$ of the 32 available strains. Both brain abscesses yielded a mixed growth of $P$. micros, "Streptococcus milleri", a Fusobacterium sp. and a Bacteroides sp. Strains of $P$. micros were also isolated from four peritonsillar abscesses and one abscess in the roof of the mouth, with streptococci and other anaerobes (Fusobacterium spp., four strains; Bacteroides spp., five strains) in all cases. Apart from one strain of $P$. heliotrinreducens from a tooth abscess, $P$. micros was the only GPAC isolated from the mouth. Antral washouts from 23 cases of sinusitis, which were usually chronic and purulent, yielded GPAC, notably $P$. magnus (10 isolates), $P$. micros (six isolates) and the only two strains of Hare group VIII; a wide range of organisms other than GPAC was also cultured. Other anaerobes were always present if $P$. micros was isolated but they were cultured from only two of 10 specimens with $P$. magnus. Four pleural empyemas yielded two strains of $P$. micros (both with fusobacteria and other anaerobes), one strain of $P$. heliotrinreducens (with "Str. milleri" and two Bacteroides spp.) and one of $P$. vaginalis (with Pseudomonas aeruginosa). There were no pure cultures of GPAC from deep sites above the diaphragm.

Abdominal and anorectal specimens yielded 38 strains $(18 \%$, table V), 23 of them from abscesses. Most groups of GPAC were represented. P. anaerobius was 
Table IV. Isolation of GPAC from abscesses

\begin{tabular}{|c|c|c|c|c|c|c|c|c|c|c|c|c|}
\hline \multirow[b]{2}{*}{ Species } & \multicolumn{11}{|c|}{ Number of isolates from abscesses of } & \multirow[b]{2}{*}{$\begin{array}{c}\text { Total } \\
(\%)\end{array}$} \\
\hline & brain & $\begin{array}{l}\text { intra- } \\
\text { oral }\end{array}$ & $\begin{array}{l}\text { skin of } \\
\text { upper } \\
\text { body }\end{array}$ & $\begin{array}{l}\text { pleural } \\
\text { empyema }\end{array}$ & breast & $\begin{array}{l}\text { abdomino- } \\
\text { pelvic }\end{array}$ & anorectal & $\begin{array}{l}\text { thigh/ } \\
\text { groin/ } \\
\text { pilonidal }\end{array}$ & scrotum & $\begin{array}{l}\text { Bartholin's } \\
\text { gland }\end{array}$ & unknown & \\
\hline P. magnus & & & 9 & & 1 & & 3 & 1 & 1 & & & $15(27)^{*}$ \\
\hline P. micros & 2 & 5 & & 2 & & 2 & 2 & & & & & $13(57)$ \\
\hline P. heliotrinreducens & & 1 & 1 & 1 & & 1 & 1 & & & & & $5(100)$ \\
\hline P. asaccharolyticus & & & 3 & & 2 & 3 & 1 & 1 & & & & $10(42)$ \\
\hline$P$. indolicus & & & & & & & & & & & 1 & $1(100)$ \\
\hline$P$. vaginalis & & & & 1 & & & & & & & & $1(10)$ \\
\hline "bGAL" group & & & & & 1 & & & 1 & & & & $2(25)$ \\
\hline $\begin{array}{l}\text { Other butyrate- } \\
\text { producing }\end{array}$ & & & & & & & & 1 & & & & l \\
\hline $\begin{array}{l}\text { P. tetradius/ } \\
P . \text { prevotii }\end{array}$ & & & & & & & & & & & & 0 \\
\hline P. anaerobius & & & & & & 3 & 6 & & 1 & 1 & & $11(37)$ \\
\hline Unsaved strains & & & 2 & & 1 & & 1 & 2 & 1 & 1 & & 8 \\
\hline Total & 2 & 6 & 15 & 4 & 5 & 9 & 14 & 6 & 3 & 2 & 1 & $67(32)$ \\
\hline
\end{tabular}

* Number in brackets refers to the percentage of all isolates of that species.

Table V. Isolation of GPAC from selected deep sites

\begin{tabular}{|c|c|c|c|c|c|c|c|c|}
\hline \multirow[b]{2}{*}{ Species } & \multicolumn{7}{|c|}{ Number of isolates from } & \multirow[b]{2}{*}{ Total $(\%)$} \\
\hline & brain abscess & intra-nasal & intra-oral & $\begin{array}{l}\text { pleural } \\
\text { empyema }\end{array}$ & $\begin{array}{l}\text { abdomino- } \\
\text { pelvic } \\
\text { abscess }\end{array}$ & $\begin{array}{l}\text { anorectal } \\
\text { abscess }\end{array}$ & $\begin{array}{c}\text { female } \\
\text { genitourinary } \\
\text { infection }\end{array}$ & \\
\hline P. magnus & & 10 & & & 5 & 3 & 3 & $21(38)^{*}$ \\
\hline P. micros & 2 & 6 & 5 & 2 & 2 & 2 & 3 & $22(96)$ \\
\hline P. heliotrinreducens & & & 1 & 1 & 1 & 1 & & $4(80)$ \\
\hline P. asaccharolyticus & & 2 & & & 3 & 1 & 5 & $11(46)$ \\
\hline P. tetradius & & & & & & & 3 & $3(100)$ \\
\hline$P$. vaginalis & & & & 1 & & & & $1(10)$ \\
\hline "bGAL" group & & & & & 1 & & 1 & $2(25)$ \\
\hline $\begin{array}{l}\text { Other butyrate- } \\
\text { producing }\end{array}$ & & & & & 1 & 1 & 1 & 3 \\
\hline P. anaerobius & & & & & 5 & 6 & 9 & $20(74)$ \\
\hline Hare group VIII & & 2 & & & & & & $2(100)$ \\
\hline Unsaved & & 3 & & & 3 & 3 & 6 & 15 \\
\hline Total & 2 & 23 & 6 & 4 & 21 & 17 & 31 & 104 \\
\hline
\end{tabular}

* Number in brackets refers to the percentage of all isolates of that species.

the commonest species, accounting for $11(34 \%)$ of the 32 available strains, but, like other GPAC from these sites, it was almost always associated with a heavy mixed growth of other organisms. Post-operative wound infections of the abdominal wall yielded four of the eight isolates of $P$. magnus (two in pure growth), but twice $P$. magnus was cultured with faecal flora from anorectal abscesses. A primary ischiorectal abscess in a previously well 27 -year-old woman yielded an isolate of $P$. asaccharolyticus in pure growth.

Genitourinary tract specimens yielded 40 (19\%) isolates. Of the nine specimens from males, one strain of $P$. magnus (in pure culture) and one of $P$. anaerobius (with a Bacteroides sp.) were from scrotal abscesses. Five strains from semen probably reflect the normal flora of the distal urethra. Of the 31 strains from women (table V), $P$. anaerobius (nine of the 25 available strains, $36 \%$ ) was again the commonest species but was not associated with any specific clinical condition. The placenta of a case of intra-uterine death yielded an isolate of $P$. magnus in pure culture. Two Bartholin's abscesses yielded a pure growth of $P$. anaerobius and a pure growth of an organism that died on subculture. The remaining strains included most groups of GPAC in association with vaginal flora. The variety of organisms isolated from IUCDs suggests that the specimen was often contaminated with vaginal flora, before or during removal.

Other sites. A strain of $P$. magnus was isolated with a coagulase-negative staphylococcus from an infected aortic graft; an infected femorofemoral graft yielded an unidentified organism similar to $P$. micros in association with Porphyromonas asaccharolytica and S. epidermidis. In 1987, there were no isolates of GPAC from blood and only two from musculoskeletal sites (one $P$. anaerobius, one unsaved), both mixed growths from cases of chronic osteomyelitis. However, in 1986, specimens from joints yielded three isolates of $P$. magnus (septic bursitis of the knee, with $S$. aureus; septic effusion of the elbow, with a coagulase-negative 
staphylococcus; and an indolent tibial sinus, with a coliform and an Enterococcus sp.) and three isolates which were not available for study.

\section{Analysis by species of GPAC}

$P$. magnus was much the commonest species of GPAC, accounting for 55 isolates-33\% of those available for identification and $c .7 \%$ of all anaerobes isolated at St Bartholomew's Hospital in 1987. It was the commonest GPAC in superficial sites ( $48 \%$ of the isolates available for identification) and antral washouts $(50 \%)$ but was relatively scarce in specimens from the abdomen and gastrointestinal tract $(25 \%)$ and the female genitourinary tract $(12 \%)$. It was the most frequent organism in abscesses (table IV) but it was recorded proportionally less often than several other species. Most of the abscesses, and nine of the 11 specimens from which it was cultured pure, were from superficial sites; $76 \%$ of isolates were cultured with aerobic or facultative organisms but only $35 \%$ with other anaerobes (table II).

Twenty-three strains of $P$. micros were isolated, 15 $(65 \%)$ of them from deep sites above the diaphragm; it was never cultured from superficial sites. $P$. micros was strongly associated with soft tissue abscesses (13 isolates, $57 \%$, including both brain abscesses, all four peritonsillar abscesses, two of the four pleural empyemas and two anorectal abscesses) but it was also cultured from three IUCDs and six purulent specimens from cases of chronic sinusitis. Unlike $P$. magnus, it was isolated with aerobic or facultative organisms in only $55 \%$ of specimens but it was invariably cultured with other anaerobes; it was frequently associated with a distinctive abscess-type flora, typically streptococci (11 isolates, eight of them "Str. milleri"), Bacteroides spp. (18 isolates) and Fusobacterium spp. (15 isolates). It was cultured less often with $S$. aureus (two isolates) than it was with Veillonella spp. (three isolates). The five isolates of $P$. heliotrinreducens were all from polymicrobial abscesses but from a wide variety of sites: a superficial skin abscess in a diabetic, a pleural empyema, and tooth, abdominal wall and perianal abscesses. The abscess flora was remarkably similar to that found with P. micros: "Str. milleri" (two isolates), Bacteroides spp. (nine isolates; all five specimens), Fusobacterium spp. (two isolates) and coliforms (two isolates).

Butyrate-producing GPAC were often very difficult to characterise satisfactorily. ${ }^{21}$ However, 24 isolates were identified as $P$. asaccharolyticus. This species was not associated with any particular disease process or anatomical site; nine isolates were from superficial sites, four from abdominal specimens and five from the female genitourinary tract. It was cultured from 10 abscesses, two in pure growth-one abscess developing from a submandibular sebaceous cyst and the ischiorectal abscess mentioned above. It was also the only isolate from a urethral swab in a case of urethritis, although its significance is questionable. It was usually isolated with aerobic or facultative organisms $(87 \%$ of specimens) and other anaerobes (79\%).

Of the other recognised butyrate-producing species, $P$. indolicus, a species of veterinary importance, ${ }^{22,23}$ was cultured on only one occasion, in pure growth from a superficial abscess. Regrettably, full clinical information was not available. The sole isolate from 1986 was cultured from a perineal abscess with faecal flora. There were only three isolates of $P$. tetradius, all from vaginal specimens, and none of $P$. prevotii. Of the five newly described species, ${ }^{16,17}$ two correspond to previously characterised groups, Hare group III with $P$. hydrogenalis ${ }^{21,24}$ and the "ADH" group with $P$. vaginalis. ${ }^{19,21}$ The two isolates of $P$. hydrogenalis came from a purulent sternotomy wound (with Escherichia coli) and an infected pacemaker site (with a "bGAL" group strain of GPAC). The five isolates of $P$. hydrogenalis in 1986 were also cultured from superficial sites (long-standing foot ulcer; preputial sac; labial cyst; mastoidectomy wound; umbilical swab). Ten isolates ( $6 \%$ of those available for study) were identified as $P$. vaginalis. Five were from post-surgical wound infections (two from the leg, two inguinal and one from the trunk), of which three were cultured with $S$. aureus and one was pure (from an infected skin graft on the leg). One was isolated from a pleural empyema with $P$ s. aeruginosa. The clinical information on the other four strains was, unfortunately, very incomplete, although two were cultured with $S$. aureus from the foot. Of the eight isolates placed in the "bGAL" group, two came from skin-related abscesses (of the breast and inguinal region) and four others from other superficial sites - a fungating carcinoma of the breast, an infected post-cardiac thigh wound, the pacemaker site mentioned above and tissue from a bed sore. Isolates of $P$. vaginalis were usually cultured with aerobes rather than with other anaerobes but "bGAL" group strains were associated with both aerobes and anaerobes (table II). The other six butyrate-producing isolates were heterogeneous. One, with a Bacteroides sp., came from a primary thigh abscess in a diabetic.

The distribution of $P$. anaerobius (27 isolates) was unique: it was not cultured from above the diaphragm but it was the commonest GPAC in gastrointestinal specimens ( 11 of the 32 available isolates, $35 \%$ ) and the female genitourinary tract (nine of $25,36 \%$ ). Only four isolates $(15 \%)$ were from superficial sites. Most isolates were cultured with aerobic or facultative organisms and anaerobes in a heavily mixed faecaltype flora. Eleven isolates were from abscesses, nine of them intra-abdominal or anorectal, which were also usually heavily mixed; the isolate from a Bartholin's abscess was the only pure culture. The one isolate of the "ivoricus" group in 1987 was from normal skin flora. The isolates from 1986 were from an IUCD, an infected leg wound (in heavily mixed culture) and the preputial sac of a case of balanitis. Both isolates of Hare group VIII ${ }^{24}$ in 1987 were in mixed culture from antral washouts from cases of chronic sinusitis; there 
was none in 1986. There were no isolates of $P$. barnesae, $P$. productus, $P$. lacrimalis, $P$. lactolyticus or Peptococcus niger in 1986 or 1987, nor of Str. parvulus, ${ }^{25}$ which has recently been placed in the genus Atopobium. ${ }^{26}$

\section{Discussion}

A standard text ${ }^{27}$ recently stated that "the need for determining [the identity of] species [of GPAC] is often questioned since differences in pathogenic potential for the various anaerobic gram-positive cocci are not well defined". This report shows clearly that there are major differences, in the frequency with which they are isolated, the sites from which they are cultured and the organisms with which they are associated. However, this survey has major limitations: firstly, it is a retrospective analysis - some of the clinical information is incomplete and $20 \%$ of the GPAC isolated in 1987 were not available for study; secondly, the patient population at St Bartholomew's Hospital is not typical, as there were few orthopaedic and no obstetric specimens. This is unfortunate as $P$. magnus is recognised as a significant cause of septic arthritis, usually in the presence of joint prostheses, ${ }^{28,29}$ and because the original descriptions of GPAC as human pathogens (in the guise of "anaerobic streptococci") came from cases of puerperal sepsis. ${ }^{30,31}$ Fortunately, this condition is now very rare in developed countries, although it may not be in the developing world. ${ }^{32}$ Regrettably, the placental specimen from which $P$. magnus was obtained in pure culture was sent from another hospital and we could not obtain more complete information on the cause of intra-uterine death. The collection and transport of specimens were not as rigorous as in some surveys, such as that of Brook; ${ }^{4}$ nevertheless, some extremely fastidious species, e.g., P. heliotrinreducens, were cultured successfully.

With these reservations, over 200 strains of GPAC were isolated in this laboratory in 1987-almost one per working day. They were cultured in pure growth from 22 specimens ( $11 \%$ of total), almost always in situations where they were of clinical significance; 67 $(32 \%)$ isolates were from abscesses. These findings agree closely with other surveys. ${ }^{1-4} P$. magnus stands out as the most pathogenic species of GPAC. It was much the commonest species overall and by far the commonest species isolated in pure culture; it was associated particularly with abscesses arising from sebaceous cysts and superficial wound infections. It was the second commonest of all anaerobes in four major surveys, those of Wren et al., ${ }^{1}$ Holland et al. ${ }^{2}$ Rosenblatt ${ }^{3}$ and Brook, ${ }^{4}$ in which it accounted for $6 \%, 12 \%, 13 \%$ and $5 \%$ of all anaerobic isolates respectively, compared to $7 \%$ in this survey. Sanderson, ${ }^{33}$ using cases from Wren's survey, described three diabetics with infections of the foot in which P. magnus was cultured pure. It was isolated from $15-20 \%$ of diabetic foot infections (abscesses, osteomyelitis and necrosis) by Wheat et al. ${ }^{34}$ The retrospective study of Bourgault et al.$^{28}$ documented 222 patients from whom $P$. magnus was isolated, in pure culture in 32 cases $(12 \%)$; it was the commonest species of GPAC isolated over a 3 -year period and was particularly associated with soft tissue and bone and joint infections. It was more usually isolated with aerobes or facultative organisms than with other anaerobes, but, in contrast to this report, only one pure culture from a sebaceous abscess was documented. Some of these cases were analysed further in a series by Fitzgerald $e t$ $a l .,{ }^{29}$ in which $P$. magnus was the commonest anaerobe in cases of post-traumatic and post-operative anaerobic septic arthritis; there are similar reports, usually associated with the presence of prosthetic implants. ${ }^{35,36}$ Brook $^{4}$ associated it with bone and chest infections. There are also case reports of fatal endocarditis, ${ }^{37}$ paravalvular abscess round a bioprosthetic aortic valve, ${ }^{38}$ purulent pericarditis and mediastinitis, ${ }^{39}$ and anaerobic necrotising pneumonia complicated by pyopneumothorax. ${ }^{40}$ These reports illustrate the range of serious and potentially fatal infections which $P$. magnus can cause; most can be linked to the skin as the source of the organism. However, the identification methods used in some of these cases are unclear or open to criticism. Recently, Edmiston et $a l .{ }^{41}$ reported that $P$. magnus was the commonest organism cultured from a series of 52 nonpuerperal breast infections; GPAC constituted $49 \%$ of all isolates and predominated in both acute and chronic cases. $P$. magnus is undoubtedly one of the commonest anaerobic pathogens; its importance, particularly in the development of post-operative wound infections and superficial soft tissue infections, deserves much fuller study.

The pathogenic potential of other species of GPAC is very poorly understood, mainly because of problems with identification, but also because most isolates come from mixed cultures, often from superficial sites where they could be part of the normal commensal flora. Therefore, it is very often difficult to know whether they are part of the disease process or are just "fellow travellers". P. micros is a good example. This species accounted for only $4 \%$ of all GPAC in Brook's survey $^{4}$ but $9 \%$ in Rosenblatt's; ${ }^{3}$ it has also been implicated in a case of vertebral osteomyelitis, ${ }^{42}$ four cases of post-operative septic arthritis, ${ }^{29}$ nine of nonpuerperal breast infection, ${ }^{41}$ five of bacteraemia ${ }^{43}$ and four diabetic foot infections. ${ }^{34}$ In this survey, it was the only GPAC isolated from peritonsillar abscesses and it may indeed by the predominant GPAC in oral pathology: it was the commonest organism $(17 \%$ of total) in a study of endodontic abscesses ${ }^{44}$ and has been associated with progressive periodontitis. ${ }^{45}$ However, these figures would presumably include $P$. heliotrinreducens, which can best be differentiated by its pre-formed enzyme profile. ${ }^{21,46} P$. micros is a slowgrowing organism that is unlikely to be cultured successfully unless grown under strictly anaerobic conditions. We found that familiarity with the highly 
distinctive colonial morphology ${ }^{21,47}$ led to a steadily increasing isolation rate, from $4.5 \%$ of all GPAC isolated in 1986 to $10 \%$ in the first half of 1987 and $19 \%$ in the second half. We believe that isolates of $P$. micros are often missed. This is even more true of $P$. heliotrinreducens, of which the colonies are less distinctive and take even longer to grow. ${ }^{46}$ In this survey, the natural history of these organisms was remarkably similar-both were isolated typically from polymicrobial abscesses in association with a distinctive group of other anaerobes. Are they just "passengers" that manage to colonise the nutritious environment of an abscess after, for instance, isolates of "Str. milleri" have done the initial damage? Or do they contribute greatly to abscess formation? In a polymicrobial specimen, it is very difficult to know. Certainly, in preformed enzyme kits, both species are highly proteolytic - more so than any other species of GPAC. In a subcutaneous abscess model in the mouse, ${ }^{48}$ abscesses were formed more easily by combinations of GPAC and facultative organisms than by GPAC alone. We suggest that with both of these species, we are seeing only "the tip of the iceberg"; it is natural to perform more thorough microbiology on important specimens such as abscesses, particularly from sites such as the brain or pleural cavity. These organisms may be present quite regularly in a wide variety of specimens, but die during transport, or be overgrown by more rapidly growing bacteria such as coliforms; they may not be visible before cultures are discarded, or they are just not recognised.

The position of $P$. asaccharolyticus is less clear-cut, both taxonomically and clinically. It accounted for $14 \%$ of all available isolates and $17 \%$ of those from abscesses, and was cultured pure in three instances. However, unlike the other three major species, it was not associated with any particular site or infection. Organisms identified as $P$. asaccharolyticus accounted for $21 \%$ of GPAC in Rosenblatt's series ${ }^{3}$ and $18 \%$ of Brook's, ${ }^{4}$ and have been isolated from two paediatric intracranial abscesses, ${ }^{49}$ five cases of bacteraemia ${ }^{43} 12$ diabetic foot infections, ${ }^{34} 12$ breast infections ${ }^{42}$ and one peritonsillar abscess. ${ }^{50}$ Standard identification manuals ${ }^{3,8,12}$ have characterised all indole-positive, butyrate-producing GPAC as $P$. asaccharolyticus or $P$. indolicus, but this group is more heterogeneous: $:^{6,19-21}$ another indole-positive species, $P$. hydrogenalis, has recently been described ${ }^{16}$ and a few isolates of $P$. vaginalis produce indole. ${ }^{21}$ There is strong genetic and phenetic evidence that $P$. asaccharolyticus as currently defined ${ }^{8}$ is not a homogeneous species $^{6,10,21}$ and may include indole-negative strains. ${ }^{21,51}$ Seven $(29 \%)$ isolates in this survey were provisionally placed in a different group $\mathbf{B},{ }^{21}$ of which three were isolated from superficial abscesses (of the face, neck and breast), two from sacral sores and two from antral washouts. Before the clinical importance of $P$. asaccharolyticus can be defined accurately, the classification needs to be improved.

This is even more true of the indole-negative, butyrate-producing species, of which there are now five $-P$. prevotii and $P$. tetradius, and the newly described $P$. lacrimalis, $P$. lactolyticus and $P$. vaginalis. ${ }^{10}$ Many studies ${ }^{6-8,19,20}$ have shown that the present classification has major deficiencies which makes analysis of clinical importance very tentative. DNADNA hybridisation studies, ${ }^{6}$ HPLC studies ${ }^{51}$ and preformed enzyme analysis ${ }^{20,21}$ agree that the type strain of $P$. prevotii is a very unusual strain of GPAC, closely related to the type strain of $P$. tetradius but not to other butyrate-producing GPAC. None of the isolates in this survey was identified as $P$. prevotii sensu stricto, and only three $(1.5 \%)$ as $P$. tetradius, all from the female genitourinary tract; this site has yielded other isolates since. Strains identified as $P$. prevotii accounted for $9 \%$ of all GPAC in Rosenblatt's series ${ }^{3}$ and $15 \%$ in that of Brook, ${ }^{4}$ and have been cultured by other workers from a similar range of clinical specimens to $P$. asaccharolyticus. ${ }^{4,29,34,42}$ However, many of these isolates may have been indole-negative strains of $P$. asaccharolyticus, ${ }^{6,21} P$. vaginalis or the "bGAL" group. The latter group is still not adequately defined (or named!) but, in this survey, $P$. vaginalis and "bGAL" group strains accounted for 18 isolates ( $11 \%$ of those available for study) and were often cultured from important specimens, particularly post-surgical wound infections. Both groups were usually isolated from skin-related sites, but whereas $P$. vaginalis was most frequently cultured with $S$. aureus, "bGAL" isolates were more likely to be cultured with other anaerobes. Isolates of $P$. hydrogenalis also came from superficial sites, but their limited number suggests that this species may be less significant. We conclude that the classification and laboratory identification of all butyrate-producing cocci need much more thorough study; in particular, the value of the indole test, on which great emphasis has been placed, ${ }^{8,10,12,13}$ is very much open to doubt. ${ }^{6,21,51,52}$

As with $P$. micros, $P$. anaerobius was associated with polymicrobial, soft-tissue abscesses; however, most isolates were from intra-abdominal sepsis or the female genitourinary tract, in association with faecal floraoften coliforms and enterococci-unlike the organisms associated with $P$. micros. It was isolated occasionally from superficial sites, but usually where faecal contamination was likely. $P$. anaerobius is the easiest species of GPAC to identify ${ }^{12,21}$ —colonies are usually visible after overnight incubation and have a characteristic "plasticine" smell-so, unlike other species, it is likely that the majority of significant isolates in this survey were cultured successfully. Its pathogenic importance in this study was much less clear-cut than that of the three other major species. Yet it has been reported from three cases of septic arthritis, ${ }^{29} 13$ diabetic foot infections, ${ }^{34}$ an endodontic abscess, ${ }^{44}$ three peritonsillar abscesses, ${ }^{50}$ three breast infection ${ }^{42}$ and a post-thoracotomy sternal wound infection ${ }^{53}-\mathrm{a}$ much wider variety of sites than recorded in this study. It accounted for $10 \%$ of GPAC in Rosenblatt's survey ${ }^{3}$ and $18 \%$ in Brook's. ${ }^{4}$ The possibility that it is an 
important component of mixed anaerobic infections, particularly gynaecological, deserves further study. The clinical contexts of the few isolates of "ivoricus" and Hare group VIII do not suggest that these groups are of much clinical importance.

Therefore, there appears to be a spectrum from mainly skin-related species ( $P$. magnus and $P$. vaginalis), through "bGAL" group strains, $P$. asaccharolyticus and $P$. anaerobius to the species associated with deep infections, $P$. micros and $P$. heliotrinreducens. The sites from which the different species were isolated correlated with the associated organisms and the proportion of aerobes to anaerobes cultured. Most anaerobic infections are believed to develop from the endogenous flora, ${ }^{5}$ and GPAC are known to be present on most body surfaces ${ }^{8,13,27,54}$ but commensal isolates of GPAC have rarely been identified to the species level. Recent studies have led to the recognition of four new species, ${ }^{16,17}$ including $P$. vaginalis, but there are undoubtedly several more species which have not yet been properly described-some of which (for instance, "bGAL", "ivoricus" and Hare group VIII strains) were isolated from clinical specimens in this survey. Therefore, further and more detailed studies of the commensal flora are needed, with the aims of identifying isolates to the species level and the description of new species. Until a more satisfactory classification for GPAC is available, a significant proportion of clinical isolates will be unidentifiable-or misidentified.

Other areas need further study, particularly culture methods. At present, primary isolation usually requires prolonged incubation - often for 5 days-by which time many isolates have been overgrown by more rapidly growing organisms, or the results are no longer of much clinical relevance; hence there is an urgent need to develop selective media that enrich for GPAC, to permit more rapid isolation. Other research should include prospective studies of the range of infections caused by GPAC, supported by careful specimen collection as detailed by Brook. ${ }^{4}$ Very little is known of the pathogenesis of infections caused by GPAC. This report cannot do more than document the association of certain species, for instance $P$. vaginalis with $S$. aureus. However, Brook and Walker ${ }^{48}$ have developed a mouse abscess model to study the importance of individual isolates in mixed cultures,

\section{References}

1. Wren MWD, Baldwin AWF, Eldon CP, Sanderson PJ. The anaerobic culture of clinical specimens: a 14-month study. $J$ Med Microbiol 1977; 10: 49-61.

2. Holland JW, Hill EO, Altemeier WA. Numbers and types of anaerobic bacteria isolated from clinical specimens since 1960. J Clin Microbiol 1977; 5: 20-25.

3. Rosenblatt JE. Anaerobic cocci. In: Lennette EH, Balows A, Hausler WJ, Shadomy HJ (ed) Manual of clinical microbiology, 4th edn. Washington, USA, American Society for Microbiology. 1985: 445-449.

4. Brook I. Recovery of anaerobic bacteria from clinical specimens in 12 years at two military hospitals. J Clin Microbiol 1988; 26: 1181-1188.

5. Finegold SM, George WL. Anaerobic infections in humans. New York, Academic Press. 1989. and have shown that only heavily capsulate isolates of anaerobes were able to induce abscesses. Recently, Krepel et al ${ }^{55,56}$ have extended the work of Edmiston et al. ${ }^{42}$ by comparing isolates from non-puerperal breast abscesses, diabetic foot ulcers and intraabdominal sites. Finding that abscess and ulcer isolates were much more likely to produce collagenase than intra-abdominal strains, they suggested that production by $P$. magnus of proteolytic enzymes could have an adjunctive effect on the development of soft-tissue infections. Studies of virulence factors might clarify the pathogenic potential of different species of GPAC.

This survey and others ${ }^{28,29}$ have shown that GPAC, particularly $P$. magnus and $P$. asaccharolyticus, can be isolated in pure culture from significant infections. We recommend that specimens to be cultured for anaerobes should include pus from superficial infections and all joint fluids, particularly when foreign material is present. Agents with known activity against GPAC, such as penicillin or metronidazole, should be considered in empirical therapy for these infections. GPAC should be fully identified by routine laboratories when they are isolated in pure growth or from important specimens such as blood and deep organ abscesses. Greater awareness of the laboratory characteristics of the different species of GPAC would increase isolation rates; colonies of $P$. micros and $P$. anaerobius, in particular, show a highly distinctive morphology. ${ }^{21}$

GPAC have received much less attention than some other groups of anaerobes, particularly clostridia and Bacteroides spp., a neglect disproportionate to their clinical importance. This report has demonstrated that different species are isolated from different infections and are associated with distinct groups of other microorganisms. The recent advances in classification and identification should stimulate more thorough study of an interesting and important group of human pathogens.

We are grateful to the staff of the Department of Medical Microbiology, St Bartholomew's Hospital, London, for their interest and co-operation, in particular I. Harrison for providing essential computer back-up. Dr A. Lovering, Southmead Hospital, Bristol, assisted with preparation of the tables. Professor D. C. E. Speller made constructive criticisms of an early draft. A generous grant from the Sir Jules Thorn Trust supported a year's research and made this study possible.

6. Ezaki T, Yamamoto N, Ninomiya K, Suzuki S, Yabuuchi E. Transfer of Peptococcus indolicus, Peptococcus asaccharolyticus, Peptococcus prevotii and Peptococcus magnus to the genus Peptostreptococcus and prnposal of Peptostreptococcus tetradius sp. nov. Int J Syst Bacteriol 1983; 33: 683-698.

7. Huss VAR, Festl H, Schleifer KH. Nucleic acid hybridization studies and deoxyribonucleic acid base compositions of anaerobic gram-positive cocci. Int J Syst Bacteriol 1984; 34: $95-101$.

8. Holdeman Moore LV, Johnson JL, Moore WEC. Genus Peptococcus Kluyver and van Niel 1936, $400^{\mathrm{AL}} \mathrm{In}$ : Sneath PHA (ed) Bergey's manual of systematic bacteriology, vol. 2. Baltimore, Williams and Wilkins. 1986: 1082-1092.

9. Taylor EA, Jackman PJH, Phillips I. The differentiation of asaccharolytic anaerobic gram-positive cocci by protein electrophoresis. J Med Microbiol 1991 ; 34 : 339-348. 
10. Ezaki T, Oyaizu H, Yabuuchi E. The anaerobic gram-positive cocci. In: Balows A et al. (eds) The prokaryotes, 2nd edn. New York, Springer-Verlag. 1992: 1879-1892.

11. Holdeman LV, Cato EP, Moore WEC. Anaerobe laboratory manual, 4th edn. Blacksburg, Anaerobe Laboratory, Virginia Polytechnic Institute and State University. 1977.

12. Sutter VL, Citron DM, Edelstein MAC et al. Wadsworth anaerobic bacteriology manual, 4th edn. Los Angeles, Star Publishing Co. 1985

13. Hillier S, Moncla BJ. Anaerobic gram-positive nonsporeforming bacilli and cocci. In: Balows A, Hausler WJ, Herrmann KL, Isenberg HD, Shadomy EP (eds) Manual of clinical microbiology, 5th edn. Washington, American Society for Microbiology. 1991: 532-535.

14. Ezaki T, Yabuuchi E. Oligopeptidase activity of gram-positive anaerobic cocci used for rapid identification. $J$ Gen Appl Microbiol 1985; 31: 255-265.

15. Schiefer-Ullrich H, Andreesen JR. Peptostreptococcus barnesae sp. nov., a gram-positive, anaerobic, obligately purineutilising coccus from chicken faeces. Arch Microbiol 1985; 143: 26-31

16. Ezaki T, Liu S-L, Hashimoto Y, Yabuuchi E. Peptostreptococcus hydrogenalis sp. nov. from human faecal and vaginal flora. Int J Syst Bacteriol 1990; 40: 305-306.

17. Li N, Hashimoto Y, Adnan S, Miura H, Yamamoto H, Ezaki T. Three new species of the genus Peptostreptococcus isolated from humans: Peptostreptococcus vaginalis sp. nov., Peptostreptococcus lacrimalis sp. nov., and Peptostreptococcus lactolyticus $\mathrm{sp}$. nov. Int J Syst Bacteriol 1992; 42: 602-605.

18. Stenson MJ, Lee DT, Rosenblatt JE, Contezac JM. Evaluation of the AnIdent system for the identification of anaerobic bacteria. Diagn Microbiol Infect Dis 1986; 5: 9-15.

19. Murdoch DA, Mitchelmore IJ, Tabaqchali S. Identification of gram-positive anaerobic cocci by use of systems for detecting pre-formed enzymes. J Med Microbiol 1988; 25 : 289-293.

20. Murdoch DA, Mitchelmore IJ, Nash RA, Hardie JM, Tabaqchali S. Preformed enzyme profiles of reference strains of gram-positive anaerobic cocci. J Med Microbiol 1988; 27: 65-70.

21. Murdoch DA, Mitchelmore IJ. The laboratory identification of gram-positive anaerobic cocci. J Med Microbiol 1991; 34 : 295-308.

22. Madsen M, Hoi-Sorensen G, Aalbaek B, Hansen JW, Bjorn H. Summer mastitis in heifers: studies of the seasonal occurrence of Actinomyces pyogenes, Peptostreptococcus indolicus and Bacteroidaceae in clinically healthy cattle in Denmark. Vet Microbiol 1992; 30: 243-255.

23. Madsen M, Aalbaek B, Hansen JW. Comparative bacteriological studies on summer mastitis in grazing cattle and pyogenes mastitis in stabled cattle in Denmark. Vet Microbiol 1992; 32: 81-88

24. Hare R. The anaerobic cocci. In: Waterson AP (ed) Recent advances in medical microbiology. London, Churchill. 1967: 284-317.

25. Hardie JM. Anaerobic streptococci. In: Sneath PHA (ed) Bergey's manual of systematic bacteriology, vol.2. Baltimore, Williams and Wilkins. 1986: 1066-1068.

26. Collins MD, Wallbanks S. Comparative sequence analyses of the 16S rRNA genes of Lactobacillus minutus, Lactobacillus rimae and Streptococcus parvulus: proposal for the creation of a new genus Atopobium. FEMS Microbiol Lett 1992; 74: $235-240$.

27. Bartlett JG. Anaerobic cocci. In: Mandell GL, Douglas RG, Bennett JE (eds) Principles and practice of infectious diseases, 3rd edn. New York, Churchill Livingstone. 1990 1867-1869.

28. Bourgault A-M, Rosenblatt JE, Fitzgerald RH. Peptococcus magnus: a significant human pathogen. Ann Int Med 1980; 93: 244-248.

29. Fitzgerald RH, Rosenblatt JE, Tenney JH, Bourgault AM Anaerobic septic arthritis. Clin Orthop 1982; 164: 141-148.

30. Schottmueller H. Zur bedeutung einiger anaeroben in der pathologie, insbesondere bie pueperalen erkrangungen. Mitt Grenzgeb Med Chir 1910; 21: 450-490.
31. Schwarz D, Dieckman WJ. Anaerobic streptococci: their role in puerperal infection. South Med J 1926; 19: 470-479.

32. Hare R, Polunin I. Anaerobic cocci in the vagina of native women in British North Borneo. J Obs Gyn Br Emp 1960; 67: 985-989.

33. Sanderson PJ. Infection of the foot with Peptococcus magnus. $J$ Clin Pathol 1977; 30: 266-268.

34. Wheat LJ, Allen SD, Henry $M$ et al. Diabetic foot infections. Bacteriologic analysis. Arch Int Med 1986; 146: 1935-1940.

35. Hunter T, Chow AW. Peptostreptococcus magnus septic arthritis-a report and review of the English literature. $J$ Rheumatol 1988; 15: 1583-1584.

36. Davies UM, Leak AM, Dave J. Infection of a prosthetic knee joint with Peptostreptococcus magnus: Ann Rheum Dis 1988; 47: 866-868.

37. Cofsky RD, Seligman SJ. Peptococcus magnus endocarditis. South Med J 1985; 78: 361-362

38. Pouedras P, Donnio PY, Sire JM, Avril JL. Prosthetic valve endocarditis and paravalvular abscess caused by Peptostreptococcus magnus. Clin Infect Dis 1992; 15: 185.

39. Phelps R, Jacobs RA. Purulent pericarditis and mediastinitis due to Peptococcus magnus. JAMA 1985; 254 : 947-948.

40. Panagou P, Papandreou L, Bouros D. Severe anaerobic necrotizing pneumonia complicated by pyopneumothorax and anaerobic monoarthritis due to Peptostreptococcus magnus. Respiration 1991; 58: 223-225.

41. Edmiston CE, Walker AP, Krepel CJ, Gohr C. The nonpuerperal breast infection: aerobic and anaerobic microbial recovery from acute and chronic disease. $J$ Infect Dis 1990; 162: 695-699.

42. Papasian CJ, McGregor DH, Hodges GR, Kennedy J. Peptostreptococcal vertebral osteomyelitis. J Clin Microbiol $1986 ; 24: 633-635$

43. Topiel MS, Simon GL. Peptococcaceae bacteraemia. Diagn Microbiol Infect Dis 1986; 4: 109-117.

44. Williams BL, McCann GF, Schoenknecht FD. Bacteriology of dental abscesses of endodontic origin. J Clin Microbiol 1983; 18: 770-774.

45. Rams TE, Feik D, Listgarten MA, Slots J. Peptostreptococcus micros in human periodontitis. Oral Microbiol Immunol 1992; 7: 1-6.

46. Murdoch DA, Mitchelmore IJ. Isolation of Peptostreptococcus heliotrinreducens from human polymicrobial abscesses. Lett Appl Microbiol 1989; 9: 223-225.

47. Murdoch DA, Mitchelmore IJ, Tabaqchali S. Peptostreptococcus micros in polymicrobial abscesses. Lancet 1988; 1 : 594.

48. Brook I, Walker RI. The role of encapsulation in the pathogenesis of anaerobic gram-positive cocci Can J Microbiol 1985; 31: 176-180.

49. Brook I. Bacteriology of intracranial abscess in children. $J$ Neurosurg 1981; 54: 484-488.

50. Jokipii AMM, Jokipii L, Sipilä P, Jokinen K. Semiquantitative culture results and pathogenic significance of obligate anaerobes in peritonsillar abscesses. J Clin Microbiol 1988; 26: 957-961.

51. Harpold DJ, Wasilauskas BL. Rapid identification of obligately anaerobic gram-positive cocci using high-pressure liquid chromatography. J Clin Microbiol 1987; 25: 996-1001.

52. Murdoch DA, Wilks M, Mitchelmore IJ, Tabaqchali S. Identification of gram-positive anaerobic cocci by gasliquid chromatography and preformed erzyme profile using a commercial kit, ATB 32A. In: Borriello SP et al (eds) Clinical and molecular aspects of anaerobes. Petersfield, Wrightson Biomedical. 1990: 285-291.

53. Brook 1. Microbiology of postthoracotomy sternal wound infection. J Clin Microbiol 1989; 27: 806-807.

54. Neut C, Lesieur V, Romond C, Beerens H. Analysis of grampositive anaerobic cocci in oral, faecal and vaginal flora. Eur J Clin Microbiol 1985; 4: 435-437.

55. Krepel CJ, Gohr CM, Edmiston CE, Farmer SG. Anaerobic pathogenesis: collagenase production by Peptostreptococcus magnus and its relationship to site of infection. $J$ Infect Dis $1991 ; 163$ : 1148-1150.

56. Krepel CJ, Gohr CM, Walker AP, Farmer SG, Edmiston CE. Enzymatically active Peptostreptococcus magnus: association with site of infection. J Clin Microbiol 1992: 30: 2330-2334. 